05

\title{
Магнитно-резонансная силовая спектроскопия массива микрополосок пермаллоя
}

\author{
(C) Е.В. СКороходов, М.В. Сапожников, В.Л. Миронов
}

Институт фризики микроструктур РАН, Нижний Новгород, Россия

I E-mail: mironov@ipmras.ru

Поступило в Редакцию 31 октября 2017 г.

Приведены результаты исследований ферромагнитного резонанса (ФМР) в массиве микрополосок пермаллоя размером $3000 \times 500 \times 30 \mathrm{~nm}$, упорядоченных на прямоугольной решетке $3.5 \times 6 \mu \mathrm{m}$, методом магнитно-резонансной силовой микроскопии (МРСМ). Анализируются зависимости МРСМ-спектров образца от расстояния зонд-образец. Показана возможность регистрации ФМРспектра одиночной микрополоски.

DOI: 10.21883/PJTF.2018.05.45707.17101

СВЧ-свойства тонкопленочных ферромагнитных наноструктур привлекают большое внимание исследователей в связи с перспективностью их применения в приборах на основе планарных волноводов [1-6]. Характеристики ферромагнитного резонанса (ФМР) в таких системах существенно зависят как от формы и размеров отдельных элементов, так и от пространственной архитектуры всего ансамбля, а также от способов возбуждения [7-10]. Традиционным методом исследования ФМР является магнитно-резонансная спектрометрия, основанная на измерении поглощения СВЧ-излучения образцом, расположенным внутри высокодобротного резонатора, во внешнем однородном магнитном поле [11]. Однако эта методика требует изготовления достаточно больших массивов идентичных элементов, что является трудоемкой технологической задачей. В последнее время получила развитие новая методика регистрации локальных СВЧ-свойств материалов и наноструктур магнитно-резонансная силовая микроскопия (МРСМ), которая сочетает в себе преимущества магнитно-силовой микроскопии и методов резонансной СВЧ-диагностики [12-18]. Основной идеей МРСМ является регистрация локального силового взаимодействия зонда магнитно- 
силового микроскопа с магнитным образцом в условиях СВЧ-накачки. При возбуждении ФМР величина статической намагниченности образца изменяется, что приводит к изменению сил, действующих на зонд со стороны образца.

В настоящей работе проведены МРСМ-исследования ФМР в массиве микрополосок пермаллоя в продольном подмагничивающем поле. Основное внимание уделяется эффектам воздействия поля зонда на ФМР отдельных полосок.

Массив микрополосок из пермаллоя $\left(\mathrm{Ni}_{80} \mathrm{Fe}_{20}\right)$ был изготовлен методами взрывной (lift-off) литографии. Слой позитивного электронного резиста полиметилметакрилата осаждался на кремниевую подложку (толщиной $500 \mu \mathrm{m})$ с помощью центрифугирования. Начальная маска в виде массива прямоугольных полосок формировалась в резисте посредством экспонирования электронным пучком в микроскопе SUPRA 50VP с литографической приставкой ELPHY PLUS (компания „CarlZeiss“, Jena). Затем облученные области резиста, соответствующие будущим полоскам, удалялись с помощью селективного травления в растворе метилизобутилкетона в изопропиловом спирте. После этого на образец напылялся тонкий (толщиной $30 \mathrm{~nm}$ ) слой пермаллоя методом магнетронного напыления. Финальный взрывной процесс проводился в ацетоне с использованием ультразвука, в результате чего оставшийся слой резиста удалялся вместе с расположенной над ним пленкой пермаллоя. Таким образом был сформирован массив ферромагнитных полосок размером $3000 \times 500 \times 30 \mathrm{~nm}$, упорядоченный на прямоугольной решетке с периодом $6 \mu \mathrm{m}$ в направлении длинной оси и $3.5 \mu \mathrm{m} \mathrm{в}$ направлении короткой оси полосок.

Исследования спектров ФМР проводились с помощью магнитнорезонансного силового микроскопа, изготовленного в ИФМ РАН на базе вакуумного сканирующего зондового микроскопа „Solver HV“ (компания „НТ-МДТ“, Зеленоград). В качестве зондового датчика использовался стандартный кантилевер NSG-1 (резонансная частота $9.2 \mathrm{kHz}$, жесткость консоли $0.03 \mathrm{~N} / \mathrm{m}$ ), на который наклеивалась частица $\mathrm{SmCo-магнита} \mathrm{размером} 20 \mu \mathrm{m}$. Для СВЧ-накачки образцов использовался перестраиваемый генератор „SPS-20“ (компания „Спектран“, Саратов). Образец располагался на планарной закороченной полосковой линии в пучности магнитного СВЧ-поля. При этом магнитная составляющая СВЧ-поля накачки была направлена вдоль короткой оси полосок. Внешнее подмагничивающее поле Н создавалось с помощью электро-

Письма в ЖТФ, 2018, том 44, вып. 5 
магнита постоянного тока (с рабочим диапазоном полей до $3 \mathrm{kOe}$ ) и было направлено вдоль длинной оси полосок. Измерения проводились в вакууме $\left(10^{-3} \mathrm{mbar}\right)$, при этом добротность механических колебаний кантилевера составляла 950.

В эксперименте в качестве спектров ФМР регистрировались зависимости амплитуды колебаний кантилевера от внешнего подмагничивающего поля. Измерения проводились при различных расстояниях между зондом и образцом $(L)$. Накачка образца производилась на частоте $f=5.8 \mathrm{GHz}$. Мощность накачки составляла $20 \mathrm{dBm}$. СВЧ-поле модулировалось по амплитуде (глубина модуляции 100\%) на резонансной частоте кантилевера. Наличие модулированного СВЧ-поля в рабочем промежутке микроскопа приводит к появлению электростатического притяжения (сила $F_{c}$ ) между образцом и кантилевером [18], которое вызывает возбуждение колебаний кантилевера (колебания, вызванные немагнитной силой). Магнитная же сила $F_{m}$, возникающая между образцом и зондом в условиях ФМР, зависит от положения зонда относительно образца и может быть как сонаправлена, так и направлена противоположно $F_{c}$. Если $F_{c}$ и $F_{m}$ сонаправлены, то это приводит к возрастанию амплитуды колебаний кантилевера в условиях ФМР, в противоположном случае в резонансе происходит уменьшение амплитуды колебаний кантилевера. Полученные в эксперименте МРСМ-спектры приведены на рис. 1, $a$.

Из этого рисунка видно, что, когда зонд располагается высоко над образцом $(L=5 \mu \mathrm{m}$, кривая 1 на рис. $1, a)$, в спектре наблюдается широкий провал вблизи значения поля 600 Ое. При уменьшении расстояния $L$ до $2 \mu \mathrm{m}$ (кривая 2 на рис. $1, a$ ) наблюдается сдвиг резонансного поля в область 625 Ое и появление пика в области 575 Ое. При дальнейшем сближении зонда и образца на расстояние $L=0.5 \mu \mathrm{m}$ (кривая 3 на рис. $1, a)$ положительный пик возрастает и сдвигается в область поля 550 Ое, а провал сдвигается в область поля 630 Ое.

На рис. 1, $b$ приведено МРСМ-изображение участка массива микрополосок, полученное при сканировании над образцом. Частота накачки составляла $5.8 \mathrm{GHz}$, подмагничивающее поле $630 \mathrm{Oe}$, расстояние между зондом и образцом $0.5 \mu \mathrm{m}$. При этом колебания кантилевера, вызванные немагнитной силой, компенсировались посредством подачи противофазного напряжения на пьезовибратор держателя зондового датчика. Из рис. $1, b$ видно, что области ФМР (максимумы амплитуды колеба-

4* Письма в ЖТФ, 2018, том 44, вып. 5 


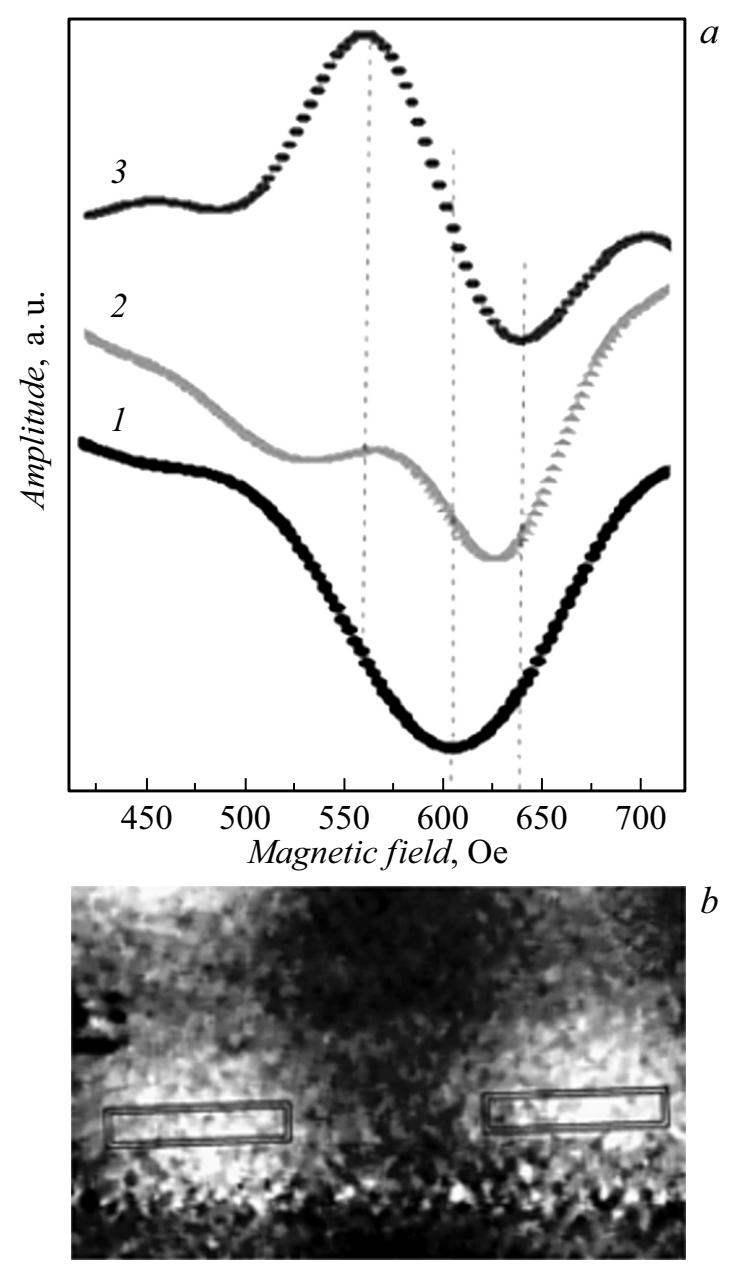

Рис. 1. $a-\mathrm{MPCM-спектры} \mathrm{ФМР} \mathrm{микрополосок} \mathrm{NiFe,} \mathrm{зарегистрированные}$ при различных расстояниях между зондом и образцом. 1 - расстояние зонд-образец $L=5 \mu \mathrm{m}, 2-L=2 \mu \mathrm{m}, 3-L=0.5 \mu \mathrm{m}$. Спектры сдвинуты по вертикальной оси для удобства сравнения. $b-$ МРСМ-изображение участка массива микрополосок на частоте $5.8 \mathrm{GHz}$ в подмагничивающем поле 630 Ое. Контурными линиями показаны положения микрополосок. Размер кадра $10 \times 6 \mu \mathrm{m}$.

Письма в ЖТФ, 2018, том 44, вып. 5 
ний кантилевера) расположены непосредственно над микрополосками пермаллоя.

Наблюдаемое изменение МРСМ-спектра связано с влиянием поля зонда на резонанс микрополосок. Выражение для силы взаимодействия между зондом и образцом, которая вызывает колебания зонда, можно записать следующим образом:

$$
\mathbf{F}=-\nabla \int_{V_{\text {sample }}}\left(\mathbf{m} \cdot \mathbf{h}_{p}\right) d V,
$$

где $\mathbf{m}$ - квазистатическая компонента намагниченности образца, которая при СВЧ-накачке осциллирует с частотой, равной резонансной частоте кантилевера [15-18], $\mathbf{h}_{p}-$ магнитное поле зонда. Раскачка кантилевера происходит за счет $z$-компоненты силы

$$
F_{z}=-\int_{V_{\text {sample }}} m_{x} \frac{\partial h_{p x}}{\partial z} d V,
$$

знак которой определяется знаком производной

$$
h_{p x}^{\prime}=\frac{\partial h_{p x}}{\partial z} .
$$

В простейшей модели, соответствующей эксперименту, зонд можно представить в виде шара [19], однородно намагниченного вдоль оси $x$ (рис. 2).

При этом пространство над образцом разбивается на несколько областей (обозначены на рисунке буквами $A$ и $B$ ), где продольные компоненты поля зонда $h_{p x}$ и градиента поля $h_{p x}^{\prime}$ имеют разный знак. Смена знака $x$-компоненты магнитного поля происходит на границе (показана штрихпунктирной линией на рис. 2), определяемой условием

$$
x= \pm \frac{z}{\sqrt{2}}
$$

При этом угол раствора области между штрихпунктирными линиями равен $71^{\circ}$. Смена знака градиента магнитного поля происходит на границе (показана штриховой линией на рис. 2), определяемой условием

$$
x= \pm \frac{z}{2} .
$$

Письма в ЖТФ, 2018, том 44, вып. 5 


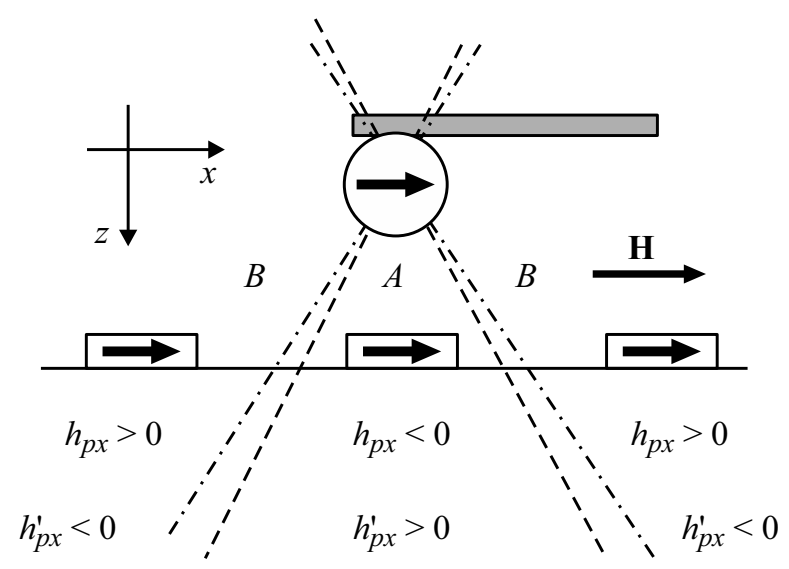

Рис. 2. Структура магнитного поля зонда над массивом микрополосок. Штрихпунктирными линиями показано сечение конических областей с различным знаком проекции поля зонда $h_{p x}$, а штриховыми линиями - с различным знаком градиента $h_{p x}^{\prime}$.

Угол раствора области между штриховыми линиями равен $54^{\circ}$ (рис. 2).

Магнитное поле зонда действует на образец и меняет условия ФМР. Действительно, резонансную частоту основной моды колебаний намагниченности ферромагнитной микрополоски можно оценить согласно формуле Киттеля [20,21] как

$$
f=\frac{\gamma}{2 \pi} \sqrt{\left(\left(H_{x}+h_{p x}\right)+\left(N_{z z}-N_{x x}\right) M_{s}\right)\left(\left(H_{x}+h_{p x}\right)+\left(N_{y y}-N_{x x}\right) M_{s}\right)},
$$

где $N_{x x}, N_{y y}, N_{z z}$ - главные значения тензора размагничивающих факторов полоски, $M_{s}$ - намагниченность насыщения пермаллоя, $\gamma$ гиромагнитное отношение. Величины $H_{x}$ и $h_{p x}-$ соответственно проекции внешнего подмагничивающего поля и магнитного поля зонда на ось $x$ (совпадает с направлением вдоль длинной стороны полосок). Из (6) видно, что поле зонда приводит к сдвигу резонансной частоты полоски, знак которого определяется знаком продольной компоненты $h_{p x}$. Поэтому в соответствии с пространственной структурой поля зонда резонансная частота полосок, расположенных в областях $B$, увеличивается (и, следовательно, уменьшается резонансное поле), по-

Письма в ЖТФ, 2018, том 44, вып. 5 
скольку $h_{p x}>0$, в то время как резонансная частота полосок внутри области $A$ уменьшается (и, следовательно, увеличивается резонансное поле), поскольку $h_{p x}<0$. Кроме того, в областях $A$ и $B$ различный знак имеет также и градиент $h_{p x}^{\prime}$. Соответствующим образом меняется и направление магнитной силы между образцом и кантилевером. Взаимодействие зонда с полосками, расположенными в областях $B$, дает положительный вклад в раскачивающую силу и увеличение амплитуды колебаний кантилевера, а взаимодействие с полосками, расположенными в области $A$, - отрицательный и уменьшение амплитуды колебаний.

На больших расстояниях $L$ зонд взаимодействует сразу с несколькими полосками, находящимися в разных резонансных условиях, что приводит к формированию широкого резонансного пика (кривая 1 на рис. $1, a)$. При уменьшении расстояния $L$ количество полосок, попадающих в область $A$, уменьшается, и при расстоянии $L=0.5 \mu \mathrm{m}$ в области $A$ оказывается лишь одна полоска, дающая пик с резонансным полем 630 Ое. Остальные близлежащие полоски оказываются расположенными в областях $B$ и формируют положительный отклик с резонансным полем 550 Ое.

Таким образом, методом магнитно-резонансной силовой спектроскопии были проведены исследования ферромагнитного резонанса массива пермаллоевых микрополосок. Показано, что структура спектров ФМР существенно зависит от расстояния между зондом и образцом. При расстоянии $5 \mu \mathrm{m}$ наблюдался один провал, вклад в который вносит несколько полосок пермаллоя. При уменьшении расстояния наблюдалось формирование двух резонансных пиков, один из которых положительный, а другой отрицательный. Данные резонансные отклики связаны с двумя группами частиц, одна из которых лежит в области, где градиент магнитного поля зонда положителен, а другая - в области, где градиент магнитного поля зонда отрицателен. При малых расстояниях между зондом и образцом удалось зарегистрировать ФМР от одиночной микрополоски.

Авторы выражают благодарность В.В. Рогову, С.Н. Вдовичеву, А.Н. Резнику за помощь при проведении экспериментов, а также А.П. Володину и А.А. Фраерману за полезные обсуждения.

Работа выполнена при поддержке Российского научного фонда (проект № 16-12-10254).

Письма в ЖТФ, 2018, том 44, вып. 5 


\section{Список литературы}

[1] Žutić I., Fabian J., Das Sarma S. // Rev. Mod. Phys. 2004. V. 76. P. 323-410.

[2] Demidov V.E., Demokritov S.O., Rott K., Krzysteczko P., Reiss G. // Appl. Phys. Lett. 2008. V. 92. P. 232503.

[3] Krawczyk M., Grundler D. // J. Phys.: Condens. Matter. 2014. V. 26. P. 123202.

[4] Duerr G., Thurner K., Topp J., Huber R., Grundler D. // Phys. Rev. Lett. 2012. V. 108. P. 227202.

[5] Tacchi S., Botters B., Madami M., Kłos J.W., Sokolovskyy M.L., Krawczyk M., Gubbiotti G., Carlotti G., Adeyeye A.O., Neusser S., Grundler D. // Phys. Rev. B. 2012. V. 86. P. 014417.

[6] Zhang V.L., Lim H.S., Lin C.S., Wang Z.K., Ng S.C., Kuok M.H., Jain S., Adeyeye A.O., Cottam M.G. // Appl. Phys. Lett. 2011. V. 99. P. 143118.

[7] Jain S., Kostylev M., Adeyeye A.O. // Phys. Rev. B. 2010. V. 82. P. 214422.

[8] Горев Р.В., Скороходов Е.В., Миронов В.Л. // ФТТ. 2016. Т. 58. В. 11. C. 2135-2139.

[9] Skorohodov E.V., Gorev R.V., Yakubov R.R., Demidov E.S., Khivintsev Yu.V., Filimonov Yu.A., Mironov V.L. // J. Magn. Magn. Mater. 2017. V. 424. P. $118-121$.

[10] Sapozhnikov M.V., Budarin L.I., Demidov E.S. // J. Magn. Magn. Mater. 2018. V. 449 P. $68-76$.

[11] Верти Джс., Болтон Джс. Теория и практические приложения метода ЭПР. М.: Мир, 1975. 552 c.

[12] Rugar D., Yannoni C.S., Sidles J.A. // Nature. 1992. V. 360. P. 563-566.

[13] Züger O., Rugar D. // Appl. Phys. Lett. 1993. V. 63. P. 2496-2498.

[14] Zhang Z., Hammel P.C., Wigen P.E. // Appl. Phys. Lett. 1996. V. 68. P. 2005-2007.

[15] Chia H.-J., Guo F., Belova L.M., McMichael D. // Phys. Rev. B. 2012. V. 86. P. 184406

[16] Guo F., Belova L.M., McMichael D. // Phys. Rev. Lett. 2013. V. 110. P. 017601.

[17] Obukhov Yu., Pelekhov D.V., Kim J., Banerjee P., Martin I., Nazaretski E., Movshovich R., An S., Gramila T.J., Batra S., Hammel P.C. // Phys. Rev. Lett. 2008. V. 100. P. 197601.

[18] Klein O., de Loubens G., Naletov V.V., Boust F., Guillet T., Hurdequint H., Leksikov A., Slavin A.N., Tiberkevich V.S., Vukadinovic N. // Phys. Rev. B. 2008. V. 78. P. 144410.

[19] Миронов В.Л., Фраерман А.А., Грибков Б.А., Ермолаева О.Л., Климов А.Ю., Гусев С.А., Нефедов И.М., Шерешевский И.А. // ФММ. 2010. Т. 110. № 7. C. 708-734.

[20] Боков В.А. Физика магнетиков. СПб.: Невский диалект, 2002. 271 с.

[21] Гуревич А.Г., Мелков Г.А. Магнитные колебания и волны. М.: Физматлит, 1994. $464 \mathrm{c}$. 